Article

\title{
Antioxidant Efficacy of Litchi (Litchi chinensis Sonn.) Pericarp Extract in Sheep Meat Nuggets
}

\author{
Arun K. Das ${ }^{1, *}$, Vincent Rajkumar ${ }^{2}$, Pramod K. Nanda ${ }^{1}$, Pranav Chauhan ${ }^{1}$, \\ Soubhagya R. Pradhan ${ }^{3}$ and Subhasish Biswas ${ }^{3}$ \\ 1 ICAR-Indian Veterinary Research Institute, Eastern Regional Station, Kolkata 700 037, India; \\ npk700@gmail.com (P.K.N.); dr.pranav.chauhan@gmail.com (P.C.) \\ 2 ICAR-Central Institute for Research on Goats, Farah, Mathura 281 122, India; vrvet@rediffmail.com \\ 3 Department of Livestock Products Technology, West Bengal University of Animal and Fishery Sciences, \\ Kolkata 700 037, India; soubhagyaovc@gmail.com (S.R.P.); lptsubhasish@gmail.com (S.B.) \\ * Correspondence: arun.das@icar.gov.in; Tel.: +91-33-2558-2965; Fax: +91-33-2556-5725 \\ Academic Editor: Dong Uk Ahn \\ Received: 12 March 2016; Accepted: 13 May 2016; Published: 18 May 2016
}

\begin{abstract}
In the present study, the efficacy of litchi fruit pericarp (LFP) extract $(0.5 \%, 1.0 \%$ and $1.5 \%$ concentration) in retarding lipid oxidation of cooked sheep meat nuggets was evaluated and compared to butylated hydroxyl toluene (BHT, $100 \mathrm{ppm}$ ). The total phenolic content and antioxidant potential of LFP extracts were determined. The thiobarbituric acid reactive substance (TBARS) values were evaluated to assess the potential of LFP extracts as natural antioxidants for oxidative stability of cooked nuggets during 12 days of refrigerated storage. Results show that total phenolics content in $10 \mathrm{mg}$ LFP powder was comparable to $100 \mathrm{ppm}$ BHT, but $15 \mathrm{mg}$ LFP powder had significantly higher $(p<0.05)$ total phenolics content and reducing power than the synthetic antioxidant. LFP extract did not affect $\mathrm{pH}$, cooking yield and the sensory attributes of cooked nuggets. Non-treated control and nuggets with $1.0 \%$ LFP extract had significantly lower total phenolics than nuggets with $1.5 \%$ extract and BHT. TBARS values were significantly lower $(p<0.05)$ throughout the storage period in cooked meat nuggets containing either LFP extract or BHT than in non-treated control. Results indicate that LFP extracts are promising sources of natural antioxidants and can potentially be used as functional food additives in meat products at $1.5 \%$ without affecting products' acceptability.
\end{abstract}

Keywords: antioxidant; lipid oxidation; litchi fruit; meat nuggets; pericarp extract; total phenolics

\section{Introduction}

Lipid oxidation and auto-oxidation play a major role in quality deterioration, reduced shelf-life and a decline in the nutritive value of muscle foods. Oxidation can also cause other detrimental effects, such as loss of essential fatty acids, flavor and discoloration, leading to changes in organoleptic attributes [1] and the formation of genotoxic and cytotoxic compounds [2]. Lipid oxidation can be influenced by several factors, such as the degree of lipid unsaturation, muscle type, animal diet and the additives used during processing, cooking and storage. Additionally, reduced $\mathrm{pH}$ of muscle food enhances lipid oxidation because of intensified autoxidation of hemoglobin [3]. To control quality deterioration in muscle foods due to lipid oxidation, synthetic antioxidants, such as butylated hydroxytoluene (BHT) and butylated hydroxy anisole (BHA), are extensively used [4,5].

Recently, the use of synthetic antioxidants has been viewed negatively due to toxicity, adverse effects on human health and food safety [6]. Therefore, research on safe and effective natural antioxidants from natural sources, such as phenolic compounds, is being explored to control lipid oxidation. Presently, natural antioxidants present in foods and other biological materials have attracted considerable attention because of their safety and potential nutritional and therapeutic 
values $[7,8]$. Phenolic extract from plants, as well as many phenolic compounds have been successfully demonstrated as natural antioxidants in retarding lipid oxidation in different foods [9]. The antioxidant effects of various plant extracts, as well as individual phenolic compounds in different muscle food systems have been evaluated and tested by various workers [1,5,7,10-12].

Litchi (Litchi chinensis Sonn.) is a tropical and subtropical fruit native to South East Asian countries and now widely cultivated throughout the world [13]. India is the second largest producer of litchi in the world after China. Litchi or lychee, a fruit with a rough brown pericarp surrounding a white flesh (aril), is popular for its delicious taste and possible health benefits [14]. Litchi fruit pericarp (LFP), which accounts for approximately $15 \%$ by weight of the whole fresh fruit, is usually discarded as waste during processing. Recent studies have reported that litchi pericarp contains significant amounts of polyphenols, flavonoids, anthocyanins and polysaccharides [15,16]. The major phenolics in LFP tissues were identified as epicatechin, procyanidin B4 and procyanidin B2 [13]. These phenolics from LFP have good antioxidant activity, anti-inflammatory, anti-carcinogenic and immune-modulatory properties $[14,17,18]$. However, to our knowledge, no studies have been conducted regarding the antioxidant potential of LFP extract in muscle foods. Herein, we report the first study of the use of LFP extract in a meat product formulation. The objectives of this study were to investigate the antioxidant potential of LFP, an abundant and under-utilized natural resource, and to evaluate its effectiveness in retarding lipid oxidation of cooked meat products.

\section{Materials and Methods}

\subsection{Preparation of Litchi Fruit Pericarp Extract}

Fresh and mature litchi fruit was purchased from the local market. The rough brown outer covers (pericarps) were carefully removed from fruits, cleaned with water and dried in an oven at $50{ }^{\circ} \mathrm{C}$. After drying, a fine powder of pericarp was made using a home grinder. Ten grams of litchi pericarp powder were added in $100 \mathrm{~mL}$ boiled distilled water and left for $1 \mathrm{~h}$ followed by filtration through Whatman No. 1 filter paper to obtain a water extract of litchi fruit pericarp.

\subsection{Sheep Meat Nugget Preparation}

Sheep meat nuggets were prepared as per the procedure outlined by Das et al. [19]. Briefly, sheep meat from leg and loin cuts was collected from the experimental slaughterhouse and kept under frozen storage at $-18{ }^{\circ} \mathrm{C}$ until further processing. Before processing, meat was thawed and cut into small cubes and minced (Tallers Ramon Model P-22, Barcelona, Spain). For meat emulsion preparation, salt, sugar, phosphate and nitrite were thoroughly mixed to the pre-weighed quantity of minced sheep meat in a bowl chopper (Seydelmann K20 Ras, Stuttgart, Germany), and ice flakes were added during chopping to maintain a lower temperature $\left(8 \pm 2{ }^{\circ} \mathrm{C}\right)$. Condiments, dry spice mix, fine wheat flour and LFP extract $(0 \%, 1 \%$ and $1.5 \%)$ were added, and chopping was continued until uniform mixing of all ingredients. About $500 \mathrm{~g}$ of emulsion were placed in a mold and steam cooked for $40 \mathrm{~min}$ to prepare cooked meat blocks. Blocks were sliced and cut into small nuggets. Sheep meat nuggets were aerobically packed in low-density polyethylene (LDPE) pouches and kept at refrigerated temperature $\left(4 \pm 1{ }^{\circ} \mathrm{C}\right)$ for further analysis. The formulation for control and treated nuggets with LFP extracts and BHT (100 ppm) is present in Table 1. The whole experiment was replicated thrice. 
Table 1. Sheep meat nuggets' formulation prepared with litchi fruit pericarp (LFP) extract and butylated hydroxytoluene (BHT).

\begin{tabular}{ccccc}
\hline Ingredients & Control & LFP (1\%) & LFP (1.5\%) & BHT (100) \\
\hline Meat (\%) & 71.1 & 70.1 & 69.5 & 71.1 \\
Salt (\%) & 1.8 & 1.8 & 1.8 & 1.8 \\
Ice flakes (\%) & 10 & 10 & 10 & 10 \\
Refined oil (\%) & 8 & 8 & 8 & 8 \\
Condiments (\%) & 4 & 4 & 4 & 4 \\
Polyphosphate (\%) & 0.3 & 0.3 & 0.3 & 0.3 \\
Dry spice mix (\%) & 1.8 & 1.8 & 1.8 & 1.8 \\
Na nitrite (ppm) (\%) & 150 & 150 & 150 & 150 \\
Wheat flour (\%) & 3 & 3 & 3 & 3 \\
LFP extract (\%) & 0.00 & 1.00 & 1.5 & - \\
BHT (100 ppm) & - & - & - & 100 \\
\hline
\end{tabular}

Control: no LFP extract; LFP (1\%): sheep meat nuggets with 1\% LFP extract (equivalent to $10 \mathrm{mg}$ LEP powder); LFP (1.5\%): sheep meat nuggets with 1.5\% LFP extract (equivalent to $15 \mathrm{mg}$ LEP powder); BHT100: sheep meat nuggets with 100 ppm BHT; Condiments: onion and garlic (4:1). Dry spice mix: aniseed, black pepper, capsicum, caraway seed, cardamom, cinnamon, cloves, coriander powder, cumin seed, turmeric and dried ginger.

\subsection{Analysis of Litchi Fruit Pericarp Extract}

\subsubsection{Analysis of Total Phenolics Content}

Total phenolics content in litchi fruit pericarp extract and BHT were determined by the Folin-Ciocalteu (F-C) method [20]. Zero-point-seven-five microliters $(0.75 \mu \mathrm{L})$ of Folin-Ciocalteu reagent were added in $100 \mu \mathrm{L}$ of different dilutions of extract, and the final volume was made ten times with distilled water $(7.65 \mathrm{~mL})$. After $5 \mathrm{~min}, 0.75 \mathrm{~mL}$ of a sodium carbonate solution $(7.5 \%)$ were added to each tube. The tubes were incubated for $90 \mathrm{~min}$ at room temperature in the dark, and absorbance (U-28000 Spectrophotometer, Hitachi, Tokyo, Japan) was measured against a blank at $725 \mathrm{~nm}$. A standard curve was plotted using different concentrations of gallic acid, and the amount of total phenolics was calculated as gallic acid equivalents (GAE) in $\mathrm{mg} / \mathrm{g}$ of dried LFP powder.

Total phenolics content in cooked sheep meat nuggets from control, BHT and extract-incorporated formulations was analyzed by using the Folin-Ciocalteu assay [21] with slight modifications. Briefly, five grams of nugget were homogenized with $25 \mathrm{~mL}$ of $70 \%$ acetone and kept overnight for extraction at refrigeration temperature. Suitable aliquots of extracts were taken in a test tube, and the volume was made to $0.5 \mathrm{~mL}$ with distilled water followed by the addition of $0.25 \mathrm{~mL}$ F-C $(1 \mathrm{~N})$ reagent and $1.25 \mathrm{~mL}$ sodium carbonate solution $(20 \%)$. The tubes were vortex mixed, and the absorbance was recorded at $725 \mathrm{~nm}$ after $40 \mathrm{~min}$.

\subsubsection{Radical Scavenging Activity Using the DPPH Assay}

The DPPH (2,2-diphenyl-1-picrylhydrazyl) assay was performed according to the method of Fargere et al. [22]. An aliquot of the various concentrations of the LFP extract and BHT was mixed with $3 \mathrm{~mL}$ of DPPH in methanol (final concentration of $250 \mu \mathrm{M}$ ), and the mixture was vortexed vigorously. Tubes were then incubated at room temperature for $30 \mathrm{~min}$ in the dark, and the absorbance was taken at $517 \mathrm{~nm}$. Radical scavenging activity (RSA) was calculated by the following equation: $\mathrm{RSA}_{\%}=\left(\right.$ Absorbance $_{\text {Control }}-$ Absorbance $_{\text {Sample }} /$ Absorbance $\left._{\text {Control }}\right) \times 100$.

\subsubsection{Ferric Reducing Antioxidant Power Assay}

The ferric reducing antioxidant power of BHT and LFP extracts was determined according to the method of Oyaizu [23]. Different concentrations of the LFP extracts and $100 \mathrm{ppm}$ BHT were mixed with $2.5 \mathrm{~mL}$ of phosphate buffer $(0.2 \mathrm{M}, \mathrm{pH} 6.6)$ and $2.5 \mathrm{~mL}$ of $1 \%(w / v)$ potassium ferricyanide. Mixtures were incubated for $20 \mathrm{~min}$ at $50{ }^{\circ} \mathrm{C}$ followed by the addition of $2.5 \mathrm{~mL}$ of $10 \%$ trichloroacetic acid and then centrifuged at $700 \times g$ for $10 \mathrm{~min}$. The supernatant $(2.5 \mathrm{~mL})$ was mixed with $2.5 \mathrm{~mL}$ of 
distilled water and $0.5 \mathrm{~mL}$ of ferric chloride $(0.1 \% w / v)$. The absorbance was measured at $700 \mathrm{~nm}$ (U-28000 spectrophotometer, Hitachi, Japan). An increase in the absorbance of the reaction mixture indicated the reducing power of the sample.

\subsection{Analysis of Cooked Sheep Meat Nuggets}

\subsection{1. $\mathrm{pH}$ and Cooking Yield of Nuggets}

The $\mathrm{pH}$ of the cooked nuggets was determined by blending $10 \mathrm{~g}$ of sample with $50 \mathrm{~mL}$ of distilled water for a minute in a homogenizer (model PT-MR-2100, Kinematica AG, Luzern, Switzerland). The $\mathrm{pH}$ values were measured using a standardized electrode attached to a digital $\mathrm{pH}$ meter (Systronics, Ahmedabad, India). The cooking yield of nuggets was determined by recording the weight of each meat block before and after cooking. The yield was calculated and expressed in percentage as: weight of cooked meat block/weight of raw meat block $\times 100$.

\subsubsection{Sensory Evaluation of Sheep Meat Nuggets}

A 10-member experienced panel evaluated sheep meat nuggets using an 8-point descriptive scale, where 8 denoted extremely desirable and 1 denoted extremely poor. Panelists were provided information about the nature of the experiments without disclosing the identity of samples and were asked to evaluate the samples for appearance, flavor, juiciness, texture and overall acceptability. Samples were warmed using a microwave oven for $1 \mathrm{~min}$ and served randomly to the panelists. The panelists were provided filtered water to rinse their mouth between samples

\subsubsection{Lipid Peroxidation of Nuggets during Storage}

Lipid peroxidation of nuggets was recorded by measuring thiobarbituric acid-reactive substances (TBARS) at an interval of 3 days during refrigerated storage. The TBARS number (mg malonaldehyde/ $\mathrm{kg}$ ) of nuggets was estimated using the extraction method outlined by Witte et al. [24] with slight modifications, as the slurry was centrifuged at $3000 \times g$ for $10 \mathrm{~min}$ (Biofuge Primo R, Heraeus, Hanau, Germany) instead of filtration through Whatman No. 42.

\subsection{Statistical Analysis}

This study was replicated thrice, and in each replication, measurements of all parameters were done in duplicate. One-way ANOVA was conducted using SPSS software (Version 20.0, IBM Corp, Armonk, NY, USA) for the calculation of different mean values ( $\mathrm{pH}$, cooking yield, total phenolics, DPPH and sensory attributes), whereas lipid peroxidation was analyzed using two-way ANOVA with treatment and storage time as the main effects. Statistical significance was identified at the $95 \%$ confidence level $(p<0.05)$.

\section{Results and Discussion}

\subsection{Total Phenolics Content of Litchi Pericarp Extract}

It is well known that plant phenolic compounds, also called polyphenols, are a large and diverse class of compounds with one or more aromatic rings bearing hydroxyl substituent(s) and have an antioxidant potential due to their possibility to act as radical scavengers or free radical terminators. Antioxidant activity is significantly correlated with phenolic and flavonoid contents [25]. Therefore, the determination of total phenolics content is one of the most important parameters to estimate the amount of antioxidants in the plant materials. Total phenolics content of different concentrations of litchi fruit pericarp extract and BHT $(100 \mathrm{pm})$ is presented in Figure 1. The results indicate that total phenolics content in $10 \mathrm{mg}$ litchi fruit pericarp powder was comparable with 100 ppm BHT, but 15 mg pericarp powder had significantly higher $(p<0.05)$ total phenolics content than $100 \mathrm{ppm}$ BHT. This study shows that litchi fruit pericarp powder is a good source of phenolic compounds containing about $18.36 \mathrm{mg}$ 
(12.42 to 27.53) GAE/g dry weight. Li et al. [17] reported that litchi fruit pericarp contains significant amounts of phenolics (9.39 to $30.16 \mathrm{mg}$ gallic acid equivalents/g fresh weight) and exhibit diverse biological activities. Zhao et al. [16] also reported a large amount of polyphenolic compounds with strong antioxidant activity in the pericarp of harvested lychee fruits. According to Zhang et al. [25], the free, bound and total phenolic contents were 66.17 to $226.03,11.18$ to 40.54 and 101.51 to $259.18 \mathrm{mg}$ of gallic acid equivalents $/ 100 \mathrm{~g}$, respectively. Higher total phenolics content in this study could be due to the variation of cultivars cultivated in the Eastern region of India and genotype differences in phenolic contents among the litchi varieties, as also reported by Li et al. [17].

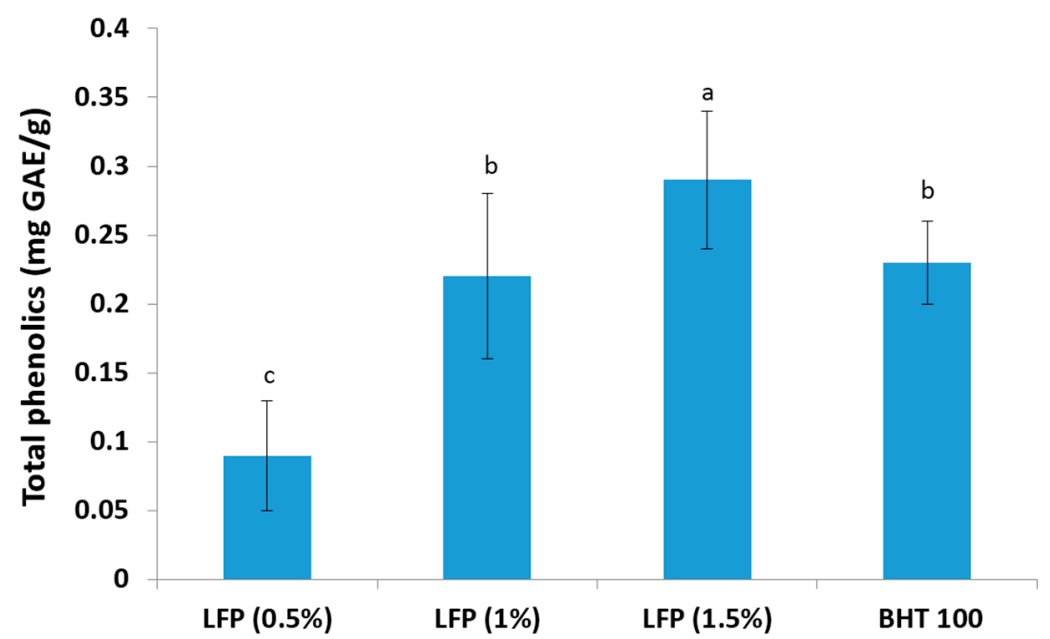

Figure 1. Total phenolics content in litchi fruit pericarp extracts $(0.5 \%, 1.0 \%$ and $1.5 \%)$ and BHT (100 ppm). Mean values bearing different superscripts $(a, b$ and $c)$ differ significantly $(p<0.05)$.

\subsection{DPPH Free Radical Scavenging Activity}

The major beneficial effect of antioxidants when used in biological or food systems include directly quenching of free radicals to terminate the radical chain reaction, chelating transition metals to suppress the initiation of radical formation and stimulating the antioxidative defense enzyme activities [26,27]. The DPPH free radical compound has been widely used to test the free radical scavenging ability of various food samples, and the antioxidant present in the extract neutralizes the DPPH by the transfer of an electron or hydrogen atom [1]. The DPPH radical scavenging activity of litchi fruit pericarp extract was detected and compared to BHT (Figure 2). The radical scavenging activity of litchi fruit pericarp extract possessed excellent antioxidant capacity, and it inhibited the activity of DPPH radicals in a dose-dependent manner. The DPPH radical scavenging activity of $15 \mathrm{mg}$ litchi fruit pericarp powder was comparable to the activity of $100 \mathrm{ppm}$ BHT. Prasad et al. [18] reported similar DPPH radical scavenging activity of a litchi fruit pericarp sample obtained by high-pressure extraction. Similarly, higher radical scavenging activity $(91.3 \%)$ has been reported for anthocyanins present in litchi pericarp [15]. Robards et al. [28] reported that there is a linear correlation between radical scavenging activity and polyphenolic content from a wide range of vegetables and fruits. In the case of litchi fruit pericarp extract, a significant correlation was also found between DPPH activities and total phenolic and total flavonoid contents [17]. They also suggested that the phenolics/flavonoids apparently contributed to the antioxidant capacity of litchi fruit pericarp. 


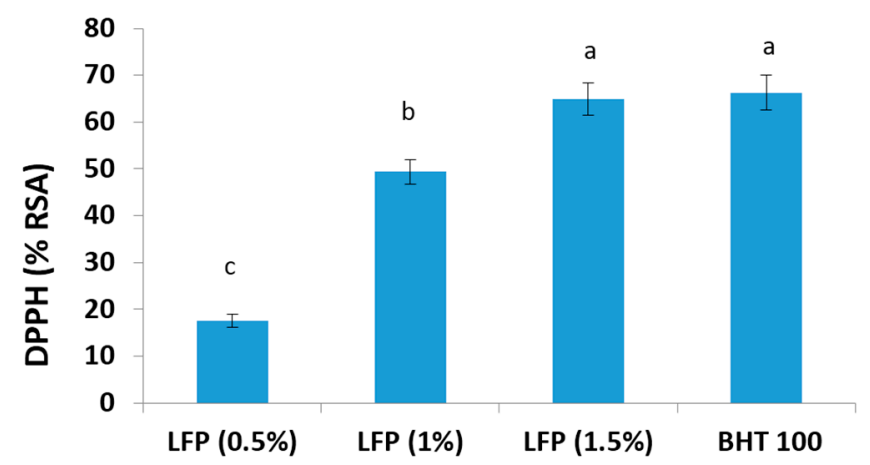

Figure 2. DPPH radical scavenging activity in litchi fruit pericarp extracts $(0.5 \%, 1.0 \%$ and $1.5 \%)$ and BHT (100 ppm). Mean values bearing different superscripts $(a, b$ and $c)$ differ significantly $(p<0.05)$.

\subsection{Ferric Reducing Antioxidant Power Assay}

The reductive capabilities of plant extracts can serve as a significant indicator of their potential antioxidant activities [29]. The potassium ferricyanide reduction method is a widely-used method for evaluating the reducing power of plant polyphenols. In this assay, litchi fruit pericarp extract reduced the iron ${ }^{3+} /$ ferricyanide complex to the ferrous form by donating an electron, and it was compared to that of BHT, which is known to be a strong reducing agent. The reducing power of a compound serves as a significant indicator of its potential antioxidant activity [7]. The reducing power of difference concentrations of litchi fruit pericarp extract and BHT is presented in Figure 3. The data obtained in this study revealed that the reducing power of extract from $10 \mathrm{mg}$ LFP powder was comparable with 100 ppm BHT, but $15 \mathrm{mg}$ powder had significantly $(p<0.05)$ higher reducing power. Moreover, higher ferric antioxidant reducing activity at a lower concentration of litchi extract indicates its potential as an antioxidant for food application at the commercial level. Previous studies have also reported that the higher reducing power is associated with more antioxidant activity [7,30].

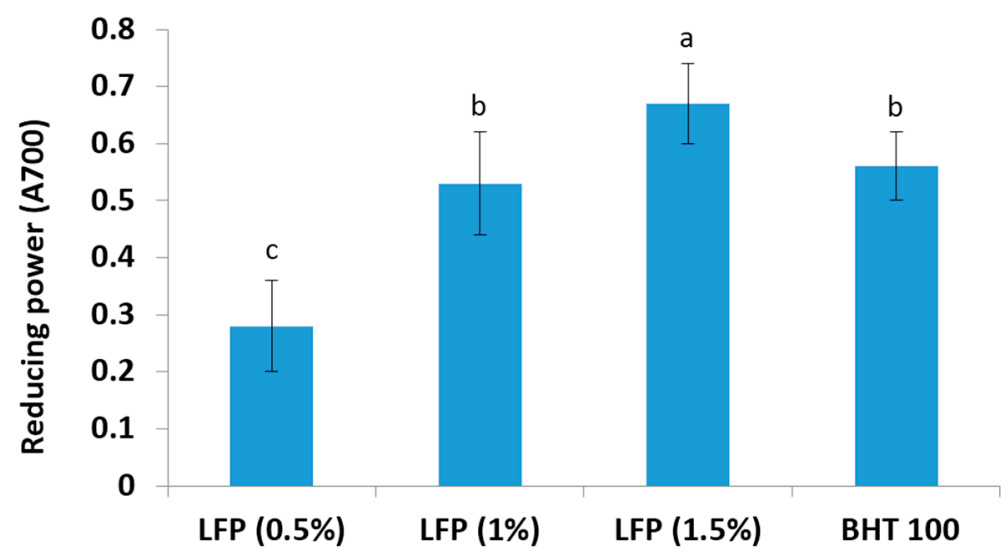

Figure 3. Ferric reducing antioxidant power of litchi fruit pericarp extracts $(0.5 \%, 1.0 \%$ and $1.5 \%)$ and BHT (100 ppm). Meat values bearing different superscripts $(a, b$ and $c)$ differ significantly $(p<0.05)$.

\subsection{Total Phenolics, $p H$ and Cooking Yield of Nuggets}

The total phenolics content, $\mathrm{pH}$ and cooking yield of nuggets with litchi fruit pericarp extract $(0 \%, 1 \%$ and $1.5 \%)$ and BHT is presented in Table 2 . The total phenolics content of sheep meat nuggets prepared with LFP extract was significantly $(p<0.05)$ higher compared to control nuggets, but nuggets with 1.5\% LFP extract had comparable total phenolics with 100 ppm BHT nuggets. Similarly, Banerjee et al. [10] reported significantly higher total phenolics content in goat meat and nuggets incorporated with BHT than control nuggets. Verma et al. [31] also reported that incorporation of guava powder in meat products' formulation significantly increased the phenolics content of final 
products than the control. Sheep meat nuggets prepared with $1 \%$ and $1.5 \%$ LFP extract had comparable $\mathrm{pH}$ value with those of control and BHT nuggets, but nuggets with $100 \mathrm{ppm}$ BHT had lower $\mathrm{pH}$ value compared to others. Similar lower $\mathrm{pH}$ values of meat products with BHT were also reported by other workers [7,32]. However, the addition of LFP extract or BHT did not affect the cooking yield of sheep meat nuggets.

Table 2. Effect of litchi fruit pericarp extracts and BHT on $\mathrm{pH}$, product yield and total phenolics of sheep meat nuggets.

\begin{tabular}{ccccc}
\hline Measurements & Control & LFP (1\%) & LFP (1.5\%) & BHT (100) \\
\hline pH & $6.21 \pm 0.03$ & $6.20 \pm 0.02$ & $6.22 \pm 0.02$ & $6.19 \pm 0.02$ \\
Cooking yield (\%) & $93.62 \pm 0.48$ & $93.29 \pm 0.36$ & $94.12 \pm 0.43$ & $93.75 \pm 0.39$ \\
Total phenolics (GAE) $\mathrm{mg} / \mathrm{g}$ & $0.05 \pm 0.01^{\mathrm{c}}$ & $0.13 \pm 0.01^{\mathrm{b}}$ & $0.17 \pm 0.01^{\mathrm{a}}$ & $0.16 \pm 0.01^{\mathrm{a}}$ \\
\hline
\end{tabular}

Control: no litchi fruit pericarp extract; LFP (1\%): sheep meat nuggets with 1\% LFP extract; LFP (1.5\%): sheep meat nuggets with 1.5\% LFP extract; BHT (100): sheep meat nuggets with $100 \mathrm{ppm}$ BHT. Means \pm SE bearing different superscripts $\left({ }^{\mathrm{a}, \mathrm{b}}\right.$ and $\left.{ }^{\mathrm{c}}\right)$ differ significantly $(p<0.05)$.

\subsection{Sensory Analysis}

The sensory attributes of different sheep meat nuggets with respect to appearance, flavor, texture, juiciness and overall acceptability are presented in Table 3. The use of BHT (100 ppm) and different concentrations of litchi pericarp extract did not influence the sensory attributes of sheep meat nuggets. The sensory attributes of control, litchi fruit pericarp extract and BHT-treated nuggets were almost similar. Similarly types of studies also report that the addition of kinnow rind powder, pomegranate rind powder and pomegranate seed powder extract do not exert any negative effect in cooked goat meat patties [12,32].

Table 3. Sensory attributes of sheep meat nuggets incorporated with litchi fruit pericarp extracts and BHT.

\begin{tabular}{ccccc}
\hline Sensory Attributes & Control & LFP (1\%) & LFP (1.5\%) & BHT (100) \\
\hline Appearance & $7.23 \pm 0.05$ & $7.22 \pm 0.06$ & $7.18 \pm 0.06$ & $7.12 \pm 0.04$ \\
Flavor & $7.06 \pm 0.6$ & $7.05 \pm 0.08$ & $7.03 \pm 0.06$ & $6.94 \pm 0.07$ \\
Texture & $7.15 \pm 0.08$ & $7.03 \pm 0.07$ & $7.01 \pm 0.06$ & $7.02 \pm 0.06$ \\
Juiciness & $7.07 \pm 0.07$ & $7.13 \pm 0.04$ & $7.15 \pm 0.05$ & $7.17 \pm 0.05$ \\
Overall acceptability & $7.18 \pm 0.05$ & $7.08 \pm 0.06$ & $7.11 \pm 0.06$ & $7.05 \pm 0.07$ \\
\hline
\end{tabular}

Control: no litchi fruit pericarp extract; LFP (1\%): sheep meat nuggets with 1\% LFP extract; LFP (1.5\%): sheep meat nuggets with 1.5\% LFP extract; BHT100: sheep meat nuggets with $100 \mathrm{ppm}$ BHT. Attributes were measured on an 8 -point scale with $8=$ extremely desirable and $1=$ extremely poor.

\subsection{Lipid Oxidation in Sheep Meat Nuggets}

The determination of the lipid oxidation was done to test the antioxidant effectiveness of litchi fruit pericarp extract as compared to control and BHT-incorporated nuggets under refrigerated storage condition (0, 3, 6, 9 and 12 days) and is presented in Figure 4. The initial concentration of TBARS in the control nuggets, as well as in all of the treated nuggets was between $0.31 \pm 0.01$ and $0.29 \pm 0.01 \mathrm{mg}$ malonaldehyde $/ \mathrm{kg}$, and the values were not significantly different. Compared to the control, the TBARS values of nuggets with $1.5 \%$ extract and 100 ppm BHT were significantly $(p<0.05)$ lower on the $3 \mathrm{rd}, 6 \mathrm{th}, 9$ th and 12 th day of refrigerated storage. TBARS values in control nuggets increased from 0.31 to $1.14 \mathrm{mg}$ malonaldehyde/ $\mathrm{kg}$ sample, whereas lipid oxidation in nuggets with $1.5 \%$ and $100 \mathrm{ppm}$ BHT remained lowest ( 0.29 to $0.92 \mathrm{mg}$ malonaldehyde/ $\mathrm{kg}$ sample) during the 12-day storage period. The antioxidant effect of LFP extract in the inhibition of lipid oxidation could be due to the presence of higher phenolics content by inhibiting free radical formation and by the propagation of the free radical chain reaction through the chelation of metals. Prasad et al. [18] found that litchi pericarp 
extract contained high phenolics and flavonoid compounds exhibiting strong antioxidant activity. This may be due to the anti-oxidative activity of phenolic compounds by scavenging free radicals, thereby decelerating lipid oxidation [33-35] or metal-chelating activity. Previous studies have also reported that incorporation of plant extracts containing phenolic and flavonoid compounds retarded lipid oxidation in meat products during storage $[9,36]$. Therefore, litchi pericarp extract $(1.5 \%)$ could be used effectively to inhibit lipid oxidation in sheep meat nuggets.

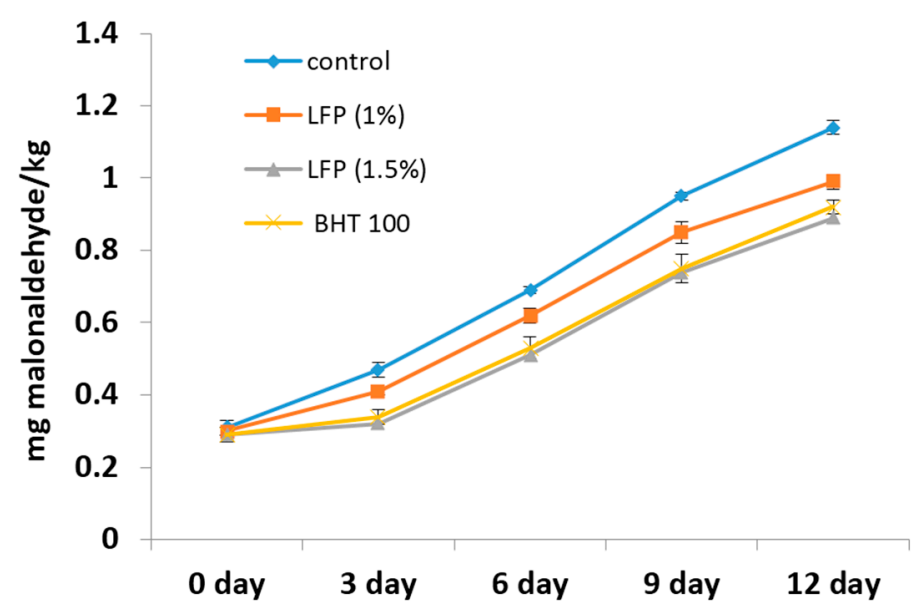

Figure 4. Thiobarbituric acid reactive substance values in sheep meat nuggets with litchi fruit pericarp extracts and BHT during refrigerated storage $\left(4 \pm 1^{\circ} \mathrm{C}\right)$.

\section{Conclusions}

The present findings indicate that litchi fruit pericarp powder is a good source of phenolic compounds having strong free radical scavenging activity and reducing power. The incorporation of pericarp extract in sheep meat nuggets did not have any adverse effect on $\mathrm{pH}$, cooking yield and sensory attributes. Litchi pericarp extract at $1.5 \%$ significantly increased the phenolic content in sheep nuggets compared to other treatments and was effective at inhibiting the lipid peroxidation of cooked nuggets similar to the synthetic antioxidant BHT (100 ppm) over a period of 12 days. Being a promising natural antioxidant, litchi fruit pericarp extract could, therefore, be used effectively to improve the product quality, stability and safety of different meat and meat products.

Acknowledgments: This work was supported by the Indian Council of Agriculture Research, Government of India, and the authors are thankful to the Director, Central Institute for Research on Goats, Mathura, India, for providing necessary facilities for conducting this research work.

Author Contributions: Arun K. Das and Vincent Rajkumar conveived and designed the experiments; Arun K. Das, Pranav Chauhan and Soubhagya R. Pradhan performed the experiments; Arun K. Das and Vincent Rajkumar analyzed the data; Arun K. Das and Pramod K. Nanda wrote the paper; Subhasish Biswas critically revised the manuscript. All authors read and approved the final manuscript.

Conflicts of Interest: The authors declare no conflict of interest.

\section{References}

1. Maqsood, S.; Benjakul, S.; Abushelaibi, A.; Alam, A. Phenolic compounds and plant phenolic extracts as natural antioxidants in prevention of lipid oxidation in seafood: A detailed review. Compr. Rev. Food Sci. Food Saf. 2014, 13, 1125-1140. [CrossRef]

2. Lapidot, T.; Granit, R.; Kanner, J. Lipid peroxidation by "free" iron ions and myoglobin as affected by dietary antioxidants in simulated gastric fluids. J. Agric. Food Chem. 2005, 53, 3383-3390. [CrossRef] [PubMed]

3. Tsuruga, M.; Matsuoka, A.; Hachimori, A.; Sugawara, Y.; Shikama, K. The molecular mechanism of autoxidation for human oxyhemoglobin: Tilting of the distal histidine causes nonequivalent oxidation in the $\beta$ chain. J. Biol. Chem. 1998, 273, 8607-8615. [CrossRef] [PubMed] 
4. Boyd, L.; Green, D.; Giesbrecht, F.; King, M. Inhibition of oxidative rancidity in frozen cooked fish flakes by tert-butylhydroquinone and rosemary extract. J. Sci. Food Agric. 1993, 61, 87-93. [CrossRef]

5. Rossi, R.; Pastorelli, G.; Cannata, S.; Tavaniello, S.; Maiorano, G.; Corino, C. Effect of long term dietary supplementation with plant extract on carcass characteristics meat quality and oxidative stability in pork. Meat Sci. 2013, 95, 542-548. [CrossRef] [PubMed]

6. Pokorný, J. Are natural antioxidants better-and safer-than synthetic antioxidants? Eur. J. Lipid Sci. Technol. 2007, 109, 629-642. [CrossRef]

7. Das, A.K.; Rajkumar, V.; Verma, A.K.; Swarup, D. Moringa oleiferia leaves extract: A natural antioxidant for retarding lipid peroxidation in cooked goat meat patties. Int. J. Food Sci. Technol. 2012, 47, 585-591. [CrossRef]

8. Mielnik, M.; Olsen, E.; Vogt, G.; Adeline, D.; Skrede, G. Grape seed extract as antioxidant in cooked, cold stored turkey meat. LWT Food Sci. Technol. 2006, 39, 191-198. [CrossRef]

9. Ahmad, S.; Gokulakrishnan, P.; Giriprasad, R.; Yatoo, M. Fruit-based natural antioxidants in meat and meat products: A review. Crit. Rev. Food Sci. Nutr. 2015, 55, 1503-1513. [CrossRef] [PubMed]

10. Banerjee, R.; Verma, A.K.; Das, A.K.; Rajkumar, V.; Shewalkar, A.; Narkhede, H. Antioxidant effects of broccoli powder extract in goat meat nuggets. Meat Sci. 2012, 91, 179-184. [CrossRef] [PubMed]

11. Qi, S.; Huang, H.; Huang, J.; Wang, Q.; Wei, Q. Lychee (Litchi chinensis Sonn.) seed water extract as potential antioxidant and anti-obese natural additive in meat products. Food Control 2015, 50, 195-201. [CrossRef]

12. Devatkal, S.K.; Narsaiah, K.; Borah, A. Anti-oxidant effect of extracts of kinnow rind, pomegranate rind and seed powders in cooked goat meat patties. Meat Sci. 2010, 85, 155-159. [CrossRef] [PubMed]

13. Duan, X.; Wu, G.; Jiang, Y. Evaluation of the antioxidant properties of litchi fruit phenolics in relation to pericarp browning prevention. Molecules 2007, 12, 759-771. [CrossRef] [PubMed]

14. Jiang, G.; Lin, S.; Wen, L.; Jiang, Y.; Zhao, M.; Chen, F.; Prasad, K.N.; Duan, X.; Yang, B. Identification of a novel phenolic compound in litchi (Litchi chinensis Sonn.) pericarp and bioactivity evaluation. Food Chem. 2013, 136, 563-568. [CrossRef] [PubMed]

15. Duan, X.; Jiang, Y.; Su, X.; Zhang, Z.Y.; Shi, J. Antioxidant properties of anthocyanins extracted from litchi (Litchi chinenesis Sonn.) fruit pericarp tissues in relation to their role in the pericarp browning. Food Chem. 2007, 101, 1365-1371. [CrossRef]

16. Zhao, M.; Yang, B.; Wang, J.; Li, B.; Jiang, Y. Identification of the major flavonoids from pericarp tissues of lychee fruit in relation to their antioxidant activities. Food Chem. 2006, 98, 539-544. [CrossRef]

17. Li, W.; Liang, H.; Zhang, M.-W.; Zhang, R.-F.; Deng, Y.-Y.; Wei, Z.-C.; Zhang, Y.; Tang, X.-J. Phenolic profiles and antioxidant activity of litchi (Litchi chinensis Sonn.) fruit pericarp from different commercially available cultivars. Molecules 2012, 17, 14954-14967. [CrossRef] [PubMed]

18. Prasad, N.K.; Yang, B.; Zhao, M.; Wang, B.S.; Chen, F.; Jiang, Y. Effects of high-pressure treatment on the extraction yield, phenolic content and antioxidant activity of litchi (Litchi chinensis Sonn.) fruit pericarp. Int. J. Food Sci. Technol. 2009, 44, 960-966. [CrossRef]

19. Das, A.K.; Rajkumar, V.; Verma, A.K. Bael pulp residue as a new source of antioxidant dietary fiber in goat meat nuggets. J. Food Process. Preserv. 2015, 39, 1626-1635. [CrossRef]

20. Singleton, V.L.; Rossi, J.A.J. Colorimetry of total phenolics with phosphomolybdic-phosphotungstic acid reagents. Am. J. Enol. Vitic. 1965, 16, 144-158.

21. Escarpa, A.; Gonzalez, M.C. Approach to the content of total extractable phenolic compounds from different food samples by comparison of chromatographic and spectrophotometric methods. Anal. Chim. Acta 2001, 427, 119-127. [CrossRef]

22. Fargere, T.; Abdennadher, M.; Delmas, M.; Boutevin, B. Determination of peroxides and hydroperoxides with 2,2-diphenyl-1-picrylhydrazyl (DPPH). Application to ozonized ethylene vinyl acetate copolymers (EVA). Eur. Polym. J. 1995, 31, 489-497. [CrossRef]

23. Oyaizu, M. Studies on products of the browning reaction. Antioxidative activities of browning reaction products prepared from glucosamine. Jpn. J. Nutr. 1986, 44, 307-315. [CrossRef]

24. Witte, V.C.; Krause, G.F.; Bailey, M.F. A new extraction method for determining 2-thiobarbituric acid values of pork and beef during storage. J. Food Sci. 1970, 35, 582-585. [CrossRef]

25. Zhang, R.; Zeng, Q.; Deng, Y.; Zhang, M.; Wei, Z.; Zhang, Y.; Tang, X. Phenolic profiles and antioxidant activity of litchi pulp of different cultivars cultivated in Southern China. Food Chem. 2013, 136, 1169-1176. [CrossRef] [PubMed] 
26. Zielinski, H.; Kozlowska, H. Antioxidant activity and total phenolics in selected cereal grains and their different morphological fractions. J. Agric. Food Chem. 2000, 48, 2008-2016. [CrossRef] [PubMed]

27. Yu, L. Free radical scavenging properties of conjugated linoleic acids. J. Agric. Food Chem. 2001, 49, 3452-3456. [CrossRef] [PubMed]

28. Robards, K.; Prenzler, P.D.; Tucker, G.; Swatsitang, P.; Glover, W. Phenolic compounds and their role in oxidative processes in fruits. Food Chem. 1999, 66, 401-436. [CrossRef]

29. Meir, S.; Kanner, J.; Akiri, B.; Philosoph-Hadas, S. Determination and involvement of aqueous reducing compounds in oxidative defense systems of various senescing leaves. J. Agric. Food Chem. 1995, 43, 1813-1819. [CrossRef]

30. Siddhuraju, P.; Becker, K. Antioxidant properties of various solvent extracts of total phenolic constituents from three different agroclimatic origins of drumstick tree (Moringa oleifera Lam.) leaves. J. Agric. Food Chem. 2003, 51, 2144-2155. [CrossRef] [PubMed]

31. Verma, A.K.; Rajkumar, V.; Banerjee, R.; Biswas, S.; Das, A.K. Guava (Psidium guajava L.) powder as an antioxidant dietary fibre in sheep meat nuggets. Asian-Australas. J. Anim. Sci. 2013, 26, 886-895. [CrossRef] [PubMed]

32. Naveena, B.; Sen, A.; Vaithiyanathan, S.; Babji, Y.; Kondaiah, N. Comparative efficacy of pomegranate juice, pomegranate rind powder extract and bht as antioxidants in cooked chicken patties. Meat Sci. 2008, 80, 1304-1308. [CrossRef] [PubMed]

33. Jovanovic, S.V.; Steenken, S.; Tosic, M.; Marjanovic, B.; Simic, M.G. Flavonoids as antioxidants. J. Am. Chem. Soc. 1994, 116, 4846-4851. [CrossRef]

34. Kondo, K.; Kurihara, M.; Miyata, N.; Suzuki, T.; Toyoda, M. Mechanistic studies of catechins as antioxidants against radical oxidation. Arch. Biochem. Biophys. 1999, 362, 79-86. [CrossRef] [PubMed]

35. Schlesier, K.; Harwat, M.; Böhm, V.; Bitsch, R. Assessment of antioxidant activity by using different in vitro methods. Free Radic. Res. 2002, 36, 177-187. [CrossRef] [PubMed]

36. Jongberg, S.; Skov, S.H.; Tørngren, M.A.; Skibsted, L.H.; Lund, M.N. Effect of white grape extract and modified atmosphere packaging on lipid and protein oxidation in chill stored beef patties. Food Chem. 2011, 128, 276-283. [CrossRef] [PubMed] 